\title{
Precarização do meio ambiente do trabalho em tempos de pandemia de Covid-19
}

\author{
Precarization of the work environment in Covid-19 pandemic times
}

\begin{abstract}
Xerxes Gusmão, D.Sc.

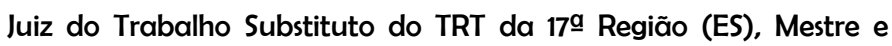
Doutor pela Universidade de Paris 1 - Panthéon-Sorbonne, Professor universitário. E-mail: xerxesgusmao@hotmail.com
\end{abstract}

RESUMO: A pandemia de Covid-19 provocou verdadeira catástrofe sanitária e econômica, no mundo inteiro. Inevitável, nesse sentido, que o meio ambiente do trabalho fosse igualmente impactado. Todavia, diversamente do que se poderia esperar, com a criação de normas que reforçassem a proteção aos trabalhadores, ameaçados pelo novo vírus, as modificações normativas adotadas no Brasil vieram a flexibilizar medidas de saúde e segurança do trabalho. Serão examinadas, desse modo, estas medidas, assim como seus reflexos para as relações de trabalho no país.

Palavras-chave: meio ambiente do trabalho, pandemia de Covid-19, modificações normativas, precarização.

\begin{abstract}
The Covid-19 pandemic caused a real health and economic catastrophe worldwide. Inevitable, in this sense, that the work environment was equally impacted. However, differently from what could be expected, with the creation of rules that reinforced the protection of workers, threatened by the new virus, the regulatory changes adopted in Brazil came to make measures of health and safety at work more flexible. In this way, these measures will be examined, as well as their impact on labor relations in the country.
\end{abstract}

Keywords: work environment, covid-19 pandemic, normative changes, precariousness. 


\section{INTRODUÇÃO}

A pandemia de Covid-19 provocou, como decorrência lógica dos seus efeitos deletérios, uma série de desafios nas mais diversas áreas, inclusive na seara laboral.

O meio ambiente do trabalho, como não poderia deixar de ser, foi fortemente atingido, em razão da necessidade de adaptação a uma nova realidade, ameaçada por um vírus altamente contagioso e potencialmente letal.

Em sentido contrário ao esperado, contudo, em vez do reforço, houve restrição a diversas normas de proteção à saúde e à segurança do trabalho, medidas que não surtiram o efeito desejável de manter empregos e salvaguardar a higidez do meio ambiente do trabalho, o qual seria atingível, caso outras medidas tivessem sido adotadas.

Dada a relevância e a polêmica acerca do tema, essas medidas restritivas e seus efeitos para as relações de trabalho serão inicialmente examinadas, passando-se, em seguida, à análise das medidas que poderiam provocar efeitos mais positivos no país.

\section{RESTRIÇÕES ÀS MEDIDAS DE SAÚDE E SEGURANÇA}

Diversamente do que se poderia imaginar em cenário de gravíssima crise sanitária, que seria o incremento de medidas de saúde e segurança do trabalho, o Poder Executivo federal fez opção oposta: adotou uma série de medidas flexibilizando normas de salvaguarda do meio ambiente do trabalho no Brasil.

O exame pormenorizado dessas medidas revela-se, por conseguinte, de relevância inquestionável, sendo realizada de forma apartada, para melhor compreensão do tema.

Urge salientar, em tempo, que essas restrições foram implementadas pela Medida Provisória (MP) n. ${ }^{\circ}$ 927/2020, de 22 de março de 2020, aprovada pela Câmara dos Deputados e que perdeu vigência em 19 de julho de 2020, por não ter sido votada no Senado Federal.

Todavia, apesar da caducidade desta Medida Provisória, seus efeitos remanescem aplicáveis ao período de vigência desta norma, de 22 de março a 19 de julho de 2020, justificando seu estudo.

Laborare. Ano IV, Número 6, Jan-Jun/2021, pp. 69-89. ISSN 2595-847X. https://revistalaborare.org/ DOl: https://doi.org/10.33637/2595-847x.2021-61 
Igualmente, sua análise serve de paradigma interpretativo para eventuais modificações normativas futuras similares, confirmando a importância de se examinar as restrições ora sub lúmen.

\subsection{SUSPENSÃO DE EXAMES MÉDICOS}

A primeira dessas medidas flexibilizadoras foi a suspensão da obrigatoriedade de realização dos exames médicos ocupacionais, clínicos e complementares, exceto dos exames demissionais, que permaneceram obrigatórios.

Trata-se da previsão do artigo 15 da Medida Provisória n. ${ }^{\circ}$ 927/2020, adotada logo no início da pandemia de Covid-19, cuja redação era a seguinte:

Art. 15. Durante o estado de calamidade pública a que se refere o art. $1^{\circ}$, fica suspensa a obrigatoriedade de realização dos exames médicos ocupacionais, clínicos e complementares, exceto dos exames demissionais.

$\S 1^{\circ}$ Os exames a que se refere o caput deste artigo serão realizados no prazo de sessenta dias, contado da data de encerramento do estado de calamidade pública.

$\S 2^{\circ} \mathrm{Na}$ hipótese de o médico coordenador de programa de controle médico e saúde ocupacional considerar que a prorrogação da realização dos exames representa risco para a saúde do empregado, o médico indicará ao empregador a necessidade de sua realização.

$\S 3^{\circ} \mathrm{O}$ exame demissional poderá ser dispensado caso o exame médico ocupacional mais recente tenha sido realizado há menos de 180 (cento e oitenta dias).

Percebe-se, assim, que a retomada desses exames médicos periódicos somente seria realizada no prazo de sessenta dias, contado da data de encerramento do estado de calamidade pública, a saber: a partir de março de 2021, eis que este estado foi prorrogado até o final de 2020, nos termos do artigo $1^{\circ}$ do Decreto Legislativo n. ${ }^{\circ} 6 / 2020$.

Cumpre, todavia, observar que, na hipótese de o médico coordenador de programa de controle médico e saúde ocupacional considerar que a prorrogação representa risco para a saúde do empregado, ele poderia indicar ao empregador a necessidade de sua realização.

Laborare. Ano IV, Número 6, Jan-Jun/2021, pp. 69-89. ISSN 2595-847X. https://revistalaborare.org/ DOI: https://doi.org/10.33637/2595-847x.2021-61 
Mesmo o exame médico demissional, em princípio mantido, poderia ser dispensado, caso o exame ocupacional mais recente tivesse sido realizado há menos de cento e oitenta dias ${ }^{1}$.

Trata-se, portanto, de medida com potencial elevado de danos à saúde do trabalhador, submetido à nova realidade de trabalho na pandemia, em muitos casos no regime do teletrabalho, longe das dependências da empresa, fato que majorava, naturalmente, os riscos de desenvolvimento de doenças decorrentes desta nova realidade, o que demandaria, ao contrário da medida adotada, uma cautela adicional com a apuração das condições de saúde do trabalhador.

Deduz-se, desse modo, que solução mais conveniente seria não a de suspender, como realizado pela Medida Provisória citada, mas sim a de se buscar formas alternativas e seguras de realização dos exames periódicos dada a sua relevância para a salvaguarda da saúde dos teletrabalhadores.

Especialmente se considerados preceitos constitucionais que regulamentam a questão, a saber: o princípio da dignidade da pessoa humana (art. $1^{\circ}$, III da Constituição Federal de $1988-\mathrm{CF} / 88$ ); o princípio do valor social do trabalho (art. $1^{\circ}$, IV da $\mathrm{CF} / 88$ ); o direito à saúde (art. $6^{\circ} \mathrm{da} \mathrm{CF} / 88$ ); o princípio da proteção do trabalhador (art. $7^{\circ}$, caput da $\mathrm{CF} / 88$ ); o direito ao meio ambiente do trabalho hígido, com a redução dos riscos inerentes ao trabalho (art. $7^{\circ}$, XXII da $\mathrm{CF} / 88$ ); o dever de colaboração para a proteção do meio ambiente, incluindo o do trabalho (art. 200, VIII c/c 225, caput da $\mathrm{CF} / 88$ ).

Este conjunto de preceitos constitui uma garantia constitucional, na visão de doutrinadores como Cláudio Brandão, como se observa do seguinte trecho da sua obra:

A correlação identificada entre os dispositivos constitucionais permite afirmar que a segurança e a saúde do trabalhador estão garantidas constitucionalmente, em face do caráter múltiplo do conceito de meio ambiente - no qual se insere o trabalho -, pressupondo a garantia de um local seguro, salubre e que assegure qualidade de vida, eliminando-se a antiga dicotomia existente entre os ambientes externo e interno da empresa (BRANDÃO, 2009, p. 105).

Donde o questionamento, por parcela considerável da doutrina, da constitucionalidade desta medida flexibilizadora ao meio ambiente do trabalho no

1 Cumpre salientar que, no texto da MP n.ㅇ 927/20 aprovado pela Câmara dos Deputados, criavam-se novas hipóteses de dispensa dos exames demissionais, além desta do texto original da MP.

Laborare. Ano IV, Número 6, Jan-Jun/2021, pp. 69-89. ISSN 2595-847X. https://revistalaborare.org/ DOI: https://doi.org/10.33637/2595-847x.2021-61 
Brasil, por pretensa violação a este arcabouço normativo que assegura amparo constitucional à saúde e à segurança do trabalho.

\subsection{SUSPENSÃO DE TREINAMENTOS}

No mesmo sentido desta tendência à flexibilização de medidas de saúde e segurança do trabalho, a Medida Provisória n. ${ }^{\circ}$ 927/2020 suspendeu a obrigatoriedade de realização de treinamentos periódicos e eventuais dos atuais empregados, previstos em normas regulamentadoras de segurança e saúde no trabalho, enquanto perdurar o estado de calamidade pública.

Consistia na redação do seu artigo 16 :

Art. 16. Durante o estado de calamidade pública a que se refere o art. $1^{\circ}$, fica suspensa a obrigatoriedade de realização de treinamentos periódicos e eventuais dos atuais empregados, previstos em normas regulamentadoras de segurança e saúde no trabalho.

$\S 1^{\circ}$ Os treinamentos de que trata o caput serão realizados no prazo de noventa dias, contado da data de encerramento do estado de calamidade pública.

$\S 2^{\circ}$ Durante o estado de calamidade pública a que se refere o art. $1^{\circ}$, os treinamentos de que trata o caput poderão ser realizados na modalidade de ensino a distância e caberá ao empregador observar os conteúdos práticos, de modo a garantir que as atividades sejam executadas com segurança.

Estes treinamentos suspensos seriam retomados no prazo de noventa dias, contado da data de encerramento do estado de calamidade pública. Uma vez mais, portanto, estaria sendo postergada medida essencial de saúde e segurança do trabalho para o ano de 2021, a partir do mês de abril ${ }^{2}$.

Houve, é verdade, previsão da possibilidade de oferecimento destes treinamentos, durante o estado de calamidade pública, na modalidade de ensino à distância, cabendo ao empregador observar os conteúdos práticos, de modo a garantir que as atividades sejam executadas com segurança.

Repete-se, neste ponto, a mesma observação apresentada no item anterior: não se afigura como razoável esta medida, pois agrava os riscos de ocorrência de acidente de

2 Reiterando-se a previsão, até 31 de dezembro de 2020, do estado de calamidade pública no Brasil, nos termos do artigo 10 do Decreto Legislativo n.o 6/2020.

Laborare. Ano IV, Número 6, Jan-Jun/2021, pp. 69-89. ISSN 2595-847X. https://revistalaborare.org/ DOl: https://doi.org/10.33637/2595-847x.2021-61 
trabalho ou de desenvolvimento de doença ocupacional pelo trabalhador, exposto a condições novas de execução das suas atividades e, por conseguinte, a riscos igualmente inéditos, mas desprovido dos treinamentos necessários para esta adaptação.

Em vez disso, seria recomendável a previsão do uso obrigatório - não do facultativo, como contido no texto normativo sob exame -, da modalidade de ensino à distância destes treinamentos, perfeitamente assimilável nesta nova realidade laboral, pois respeitando as normas de isolamento social e tecnicamente viável ${ }^{3}$.

Outrossim, convém destacar que o mesmo questionamento à constitucionalidade da medida, existente no caso dos exames médicos, ocorre quanto a esta medida, sob fundamento de violação ao arcabouço normativo constitucional mencionado no item anterior.

Afigura-se, efetivamente, salvo melhor juízo, como de superação inviável o conflito entre essas suspensões de medidas essenciais para a garantia do meio ambiente do trabalho hígido e os preceitos constitucionais mencionados.

Isto porque o dever do Estado, enquanto garantidor destes preceitos constitucionais é o de assegurar, não o de mitigar, a tutela à saúde do trabalhador.

Interessantes, nesse diapasão, as observações seguintes do doutrinador José Aparecido Ribeiro de Oliveira Silva acerca do direito do trabalhador à abstenção por parte do Estado sobre o tema:

Não há muito que considerar sobre este item, porque se afigura bastante óbvio que a interferência do Estado no exercício do direito à saúde por parte do trabalhador ou de qualquer pessoa não pode ser tolerada. Se a saúde é um direito humano fundamental, qualquer agente do Estado tem de envidar todos os esforços para a efetivação do direito, nunca atrapalhar ou mesmo impedir o seu exercício. Com efeito, a única interferência que se pode aceitar nesse campo é a que visa a proporcionar a satisfação do direito à proteção à saúde. Não pode nenhum agente do Estado atuar no sentido de dificultar ou impossibilitar o recurso aos meios técnicos e aos serviços existentes para o amparo à saúde da população em geral e dos trabalhadores em particular. (SILVA, 2008, p. 172).

3 Nesse sentido, diversas empresas se adaptaram à nova realidade, adotando o teletrabalho, o que tornava perfeitamente viável a adoção dos treinamentos na modalidade à distância.

Laborare. Ano IV, Número 6, Jan-Jun/2021, pp. 69-89. ISSN 2595-847X. https://revistalaborare.org/ DOI: https://doi.org/10.33637/2595-847x.2021-61 
Conclui-se, destarte, que o dever do Estado, no atual cenário de pandemia, era o de reforçar a exigência de exames e treinamentos, não podendo, sem malferir os preceitos constitucionais mencionados, mitigá-la.

Trata-se do que renomado especialista do tema, Sebastião Geraldo de Oliveira, denomina de princípio do risco mínimo regressivo (OLIVEIRA, 2005), a saber: não se pode reduzir, mas unicamente incrementar o sistema de proteção ao meio ambiente do trabalho.

Exatamente essa a posição de outro respeitado especialista do tema no país, Raimundo Simão de Melo, como se depreende do trecho a seguir de artigo de sua autoria:

Neste momento de pandemia do novo coronavírus há quem indague se é possível flexibilizar o conceito de meio-ambiente equilibrado e da consequente Covid-19. Sobre esta questão cabe ponderar que o meio ambiente do trabalho sadio e adequado é um direito fundamental inerente à própria condição humana, porque com ele se visa proteger a saúde e a vida das pessoas. Desta forma, não é possível flexibilizar o conceito de meio ambiente e muito sua aplicação em tempos de pandemia. Ao contrário, é necessário enfatizar mais ainda a sua importância e a adoção de medidas de proteção aos trabalhadores, porque o vírus da Covid-19 proporciona risco grave e iminente não somente para os trabalhadores, mas para todas as pessoas do planeta (MELO, 2020, p. 2).

Note-se a pertinência da alusão do autor à importância não somente para os trabalhadores, mas a todas as pessoas do mundo, da manutenção de um meio ambiente do trabalho hígido e equilibrado, no atual cenário de pandemia de Covid-194.

Somente por meio dessa prevenção coletiva seria possível se atingir, em realidade tão delicada, o objetivo contido no preceito constitucional já mencionado, do risco mínimo regressivo.

\subsection{COVID 19 COMO DOENÇA OCUPACIONAL}

De todas as modificações analisadas no presente texto, sem nenhuma dúvida a mais polêmica e que enseja maior curiosidade, no meio jurídico e fora dele, refere-se à eventual natureza ocupacional da Covid-19.

4 Num mundo globalizado, um vírus se espalha rapidamente, em todo o planeta. Donde a necessidade de um combate igualmente global e reforçado.

Laborare. Ano IV, Número 6, Jan-Jun/2021, pp. 69-89. ISSN 2595-847X. https://revistalaborare.org/ DOl: https://doi.org/10.33637/2595-847x.2021-61 
Sucede que, se naturalmente este tema surgiria no debate sobre a Covid-19 e seus efeitos nas relações de trabalho, o Poder Executivo federal agregou um fator altamente polêmico às discussões.

Consistiu no teor do artigo 29 da Medida Provisória n. ${ }^{\circ}$ 927/2020, que afastava expressamente a natureza ocupacional da Covid-19 contraída por empregado, salvo prova do nexo causal entre a patologia e o labor prestado para o empregador.

Eis a sua redação: “Art. 29. Os casos de contaminação pelo coronavírus (covid-19) não serão considerados ocupacionais, exceto mediante comprovação do nexo causal".

Parcela amplamente majoritária da doutrina considerava o afastamento apriorístico da natureza ocupacional da Covid-19 como excessivamente rigoroso com o trabalhador, pois the impunha ônus do qual dificilmente poderia se desvencilhar.

Neste caso, o Supremo Tribunal Federal (STF) proferiu rápida decisão, visando apaziguar a cizânia, em decisão prolatada no dia 29 de abril de 2020, no bojo de diversas Ações Diretas de Inconstitucionalidade (ADI), a saber: 6342, 6344, 6346, $6348,6349,6352$ e 6354.

Para a maioria dos ministros do STF, a exigência de que o empregado comprove a relação entre a contaminação por coronavírus e o trabalho impõe uma "prova diabólica", ante a impossibilidade de definir com precisão em qual circunstância a doença foi contraída.

Ademais, a maioria dos ministros considerou que esta regra do artigo 29 da MP n. ${ }^{\circ}$ 927/2020 foge da própria finalidade desta MP, de compatibilizar os valores sociais do trabalho, perpetuando o vínculo trabalhista, com a livre iniciativa, mantendo, mesmo que abalada, a saúde financeira de milhares de empresas.

Guilherme Guimarães Feliciano e Paulo Roberto Lemgruber Ebert destacam, sobre a questão, que:

Um obstáculo relevante para a aferição dessa responsabilidade apresentou-se com teor do artigo 29 da MP 927/2020, ao estabelecer que "os casos de contaminação pelo coronavírus (Covid-19) não serão considerados ocupacionais, exceto mediante comprovação do nexo causal". Criava-se uma inexplicável inversão do ônus da prova em desfavor do trabalhador, na contramão da tendência universal do Direito Previdenciário (cada vez mais permeável às presunções de causalidade, como se vê, p. ex., no art. 21-A da Lei 8.213/1991, que trata do nexo técnico

Laborare. Ano IV, Número 6, Jan-Jun/2021, pp. 69-89. ISSN 2595-847X. https://revistalaborare.org/ DOI: https://doi.org/10.33637/2595-847x.2021-61 
epidemiológico). Mas, como esclarecido, a sua eficácia foi suspensa pelo Excelso Pretório, em sessão do último dia 29 de abril, exatamente porque fugiria da finalidade maior da MP 927/2020 - na dicção do Min. Alexandre de Moraes, "compatibilizar o valor social do trabalho, perpetuando o vínculo trabalhista, com a livre iniciativa, mantendo, mesmo que abalada, a saúde financeira de milhares de empresas" - e engendraria injustificáveis dificuldades para trabalhadores dos mais diversos segmentos, inclusive os ativados em atividades essenciais (Decreto n. 10.282/2020), constantemente expostos a intensos riscos de contaminação. Em termos conceituais e práticos, todavia, o referido art. 29 em nada obstaria a aplicação do art. $14, \S 1^{\circ}$, da Lei n. 6.938/1981, já que esse último dispositivo diz com a inexigibilidade forense de se demonstrar o elemento subjetivo da ação ou omissão do imputado (= dolo ou culpa por negligência, imperícia ou imprudência), não com a questão do nexo de causalidade (ou, mais largamente, com o nexo de imputação normativa). (FELICIANO e EBERT, 2020, p. 15-16)

Desse modo, segundo essa decisão da Corte Suprema, ao prever o examinado artigo da MP que casos de contaminação pela Covid-19 não configurariam doença ocupacional, exceto mediante comprovação de nexo causal, ele estaria ofendendo inúmeros trabalhadores de atividades essenciais que continuam expostos ao risco, razão pela qual o Plenário do STF suspendeu a eficácia do artigo 29 da $\mathrm{MP}$ n. ${ }^{\circ}$ 927/2020, por inconstitucionalidade.

É possível, assim, delimitar dois conceitos fundamentais adotados pelo STF: o primeiro é o de atividade essencial, para cujos trabalhadores não é justo excluir o nexo causal, pelo contrário, o mais justo seria alguma presunção militando em seu favor; o segundo é o de risco acentuado, para cujos trabalhadores, que não podem deixar de trabalhar, tampouco se revela justa a exclusão apriorística de nexo.

Conclui-se, portanto, que para os trabalhadores em atividades essenciais ou expostos a risco acentuado, presume-se o nexo causal da Covid-19 com o trabalho.

Diversa não poderia ser a conclusão, em respeito aos preceitos constitucionais já mencionados, mas igualmente ao princípio da solidariedade, presente no ordenamento jurídico nacional e internacional, e mais do que nunca atual, em meio à pandemia.

Interessantes, nesse diapasão, as observações de Guilherme Guimarães Feliciano e Rodrigo Trindade, ao examinarem os efeitos da Declaração de Filadélfia e sua relação com a Covid-19:

Neste ano de 2020, o $76^{\circ}$ aniversário da declaração ocorre em meio a outro momento raro de provação da humanidade: a pandemia da covid-19. E, mais uma

Laborare. Ano IV, Número 6, Jan-Jun/2021, pp. 69-89. ISSN 2595-847X. https://revistalaborare.org/ DOI: https://doi.org/10.33637/2595-847x.2021-61 
vez, o vórtice da história reclama um repensar dos caminhos. (FELICIANO e TRINDADE, 2020)

Para as demais hipóteses, apesar da relevante cizânia doutrinária acerca dos efeitos desta decisão, é possível afirmar, de forma segura, que deixou de existir a presunção de ausência de nexo causal entre a Covid-19 e o labor prestado ao empregador, devendo-se examinar cada caso concreto de acordo com os critérios ordinários de distribuição do ônus da prova, que incluem a distribuição dinâmica ${ }^{5}$.

Relevante destacar, por fim, que alguns doutrinadores sustentam a existência de uma espécie de "ratio decidendi" oriunda desta decisão do STF, a saber: toda vez que houver normas que excluam aprioristicamente qualquer presunção de nexo causal para doenças endêmicas, pandêmicas, epidêmicas, tal previsão será inconstitucional para trabalhadores que não podem parar, por serem essenciais, e que continuam trabalhando neste período.

Nesse sentido, nova norma eventualmente adotada no futuro, que exclua o nexo da Covid-19 com o trabalho, seria igualmente inconstitucional, com base neste precedente.

Ainda que não se admita esta tese, que nos parece extremamente sólida, fato é que a decisão do STF, indicando a impossibilidade de afastamento apriorístico do nexo causal entre a Covid-19 e o trabalho prestado, inibirá futuras normas que busquem repetir o procedimento, pois efetivamente dotado de mecanismo que se afigura extremamente injusto, ao atribuir ônus excessivo aos trabalhadores.

\subsection{RESTRIÇÃO À ATUAÇÃO DA FISCALIZAÇÃO}

Modificação adicional realizada por norma criada neste período de pandemia de Covid-19 consistiu na restrição à atuação da fiscalização do trabalho.

Eis a redação original do artigo 31 da Medida Provisória n. ${ }^{\circ}$ 927/2020, responsável por esta estipulação:

Art. 31. Durante o período de cento e oitenta dias, contado da data de entrada em vigor desta Medida Provisória, os Auditores Fiscais do Trabalho do Ministério da Economia atuarão de maneira orientadora, exceto quanto às seguintes irregularidades:

5 Pois prevista em dispositivos normativos expressos, o artigo 818, §1으 da Consolidação das Leis Trabalhistas (CLT) e o artigo 373, \$1 do Código de Processo Civil (CPC).

Laborare. Ano IV, Número 6, Jan-Jun/2021, pp. 69-89. ISSN 2595-847X. https://revistalaborare.org/ DOI: https://doi.org/10.33637/2595-847x.2021-61 
I - falta de registro de empregado, a partir de denúncias; II - situações de grave e iminente risco, somente para as irregularidades imediatamente relacionadas à configuração da situação; III - ocorrência de acidente de trabalho fatal apurado por meio de procedimento fiscal de análise de acidente, somente para as irregularidades imediatamente relacionadas às causas do acidente; e IV - trabalho em condições análogas às de escravo ou trabalho infantil.

Houve, desde a promulgação desta norma, críticas exacerbadas a este artigo, por restringir uma fiscalização que se revelava, mais do que nunca, essencial para salvaguardar a higidez do meio ambiente do trabalho, em meio a uma gravíssima crise sanitária que demandava adaptações radicais e urgentes do local de trabalho.

Ocorre que, igualmente neste caso, houve rápido pronunciamento judicial sobre o tema: o Plenário do C. STF, por maioria de votos, no julgamento da medida liminar de diversas ADI (6342, 6344, 6346, 6348, 6349, 6352 e 6354), em decisão de 29 de abril de 2020, considerou inconstitucional esse artigo 31 da MP n. ${ }^{\circ}$ 927/20.

O fundamento seria o de que, ao restringir a atuação dos auditores fiscais do trabalho, esse artigo atenta contra a saúde dos empregados, não auxilia o combate à pandemia e diminui a fiscalização, no momento em que vários direitos trabalhistas estão em risco.

Como se trata de decisão com efeitos vinculantes, ainda que de natureza provisória por ser liminar, não decisão definitiva -, ela se reveste de dupla relevância: por um lado, torna-se precedente jurisprudencial, de cumprimento obrigatório para os demais ramos do Judiciário; por outro lado, cria-se uma referência, a ser adotada em julgamentos futuros sobre temas similares.

Em outras palavras: medidas restritivas de normas que salvaguardam a saúde dos empregados, sem vinculação direta ao combate à pandemia e que coloquem em risco direitos trabalhistas, poderão, em decisões a serem proferidas para casos futuros, ser consideradas inconstitucionais, com este mesmo fundamento.

Vale repisar o fato de que o meio ambiente do trabalho se reveste de tutela constitucional, a qual não pode ser afastada, mas, ao contrário, reforçada em momento de disseminação de um vírus tão perigoso como a Covid-19.

Essa vinculação constitucional é analisada de modo esclarecedor por Guilherme Guimarães Feliciano e Paulo Roberto Lemgruber Ebert, no seguinte trecho de artigo sobre o tema:

Laborare. Ano IV, Número 6, Jan-Jun/2021, pp. 69-89. ISSN 2595-847X. https://revistalaborare.org/ DOl: https://doi.org/10.33637/2595-847x.2021-61 
Ante a laicidade do Estado, cidadãos devem ser sobretudo fiéis à Constituição; e, a partir dela, compreender as leis e organizar deontologicamente a realidade. (...) Neste momento, não cabem atalhos de neutralidade. A vontade primígena das constituições democráticas é a promoção da dignidade humana; e, portanto, a preservação da vida. Tempos de crise não são tempos para o arrefecimento de direitos fundamentais; antes, são tempos para a sua redobrada afirmação.65 Juristas e tribunais devem compreender essa fatídica verdade, porque a utilidade última do Direito é mesmo a perpetuação da vida e do nosso modo de ser. E a alternativa aos resistentes será, o mais das vezes, o recolhimento prematuro aos vestíbulos da obsolescência. (FELICIANO e EBERT, 2020, p. 23)

Note-se, por derradeiro, que se inseririam nesta situação, a nosso sentir, as hipóteses examinadas tanto no da fiscalização do trabalho quanto nos três itens anteriores, pois os fundamentos para declaração da inconstitucionalidade daquelas medidas seriam os mesmos.

\subsection{JORNADA NO TELETRABALHO}

Disposição adicional destaca-se, acerca do meio ambiente do trabalho, referente à inaplicabilidade aos seus teletrabalhadores do regime do labor em teleatendimento e telemarketing, nos termos do artigo 33 da Medida Provisória n. ${ }^{\circ}$ 927/2020:

Art. 33. Não se aplicam aos trabalhadores em regime de teletrabalho, nos termos do disposto nesta Medida Provisória, as regulamentações sobre trabalho em teleatendimento e telemarketing, dispostas na Seção II do Capítulo I do Título III da Consolidação das Leis do Trabalho, aprovada pelo Decreto-Lei n. ${ }^{\circ} 5.452$.

Consequência dessa exclusão é a inaplicabilidade aos teletrabalhadores da jornada especial de seis horas por dia ou de trinta e seis horas semanais, presente no teleatendimento.

Pelo contrário: resta aplicável ao empregado em regime de teletrabalho a regulamentação anterior, inserida no texto celetista pela Lei n. ${ }^{\circ}$ 13.467/2017, pela qual não lhe é assegurada sequer a jornada ordinária de oito horas diárias, não lhe sendo devidas, por conseguinte, horas extras além da oitava diária, na forma do artigo 62, III da CLT.

Laborare. Ano IV, Número 6, Jan-Jun/2021, pp. 69-89. ISSN 2595-847X. https://revistalaborare.org/ DOI: https://doi.org/10.33637/2595-847x.2021-61 
Cumpre destacar, contudo, que essa ausência de limite da jornada é uma regra geral, oriunda da presunção de inexistência de controle do período efetivo de labor do teletrabalhador; ela é, portanto, afastada em caso de prova de que a jornada era efetivamente controlada pelo empregador.

Distinta não poderia ser a conclusão, sob pena de se consagrar situação de ficção jurídica (de ausência de controle da jornada que, na realidade, existia), contrária a princípio essencial do Direito do Trabalho, da primazia da realidade.

Ensejaria, ademais, precarização indevida das condições de labor do teletrabalhador, decorrente de uma jornada devidamente controlada, mas excessivamente elastecida e não integralmente remunerada, menoscabando, por conseguinte, $o$ direito fundamental do teletrabalhador ao meio ambiente hígido do trabalho, nos termos do artigo $7^{\circ}$, XXII da CF/88.

Outrossim, ainda no tocante à jornada de trabalho do teletrabalhador, foi adotada medida bastante polêmica pelo parágrafo $5^{\circ}$ do artigo $4^{\circ}$ da Medida Provisória n. ${ }^{\circ}$ 927/2020, cuja redação segue:

$\S 5^{\circ} \mathrm{O}$ tempo de uso de equipamentos tecnológicos e de infraestrutura necessária, assim como de softwares, de ferramentas digitais ou de aplicações de internet utilizados para o teletrabalho fora da jornada de trabalho normal do empregado, não constitui tempo à disposição, regime de prontidão ou de sobreaviso, exceto se houver previsão em acordo individual ou em acordo ou convenção coletiva de trabalho.

Trata-se, como se nota, de afastamento, como regra geral, do tempo de uso de ferramentas digitais pelo teletrabalhador da sua jornada de trabalho, desde que tal uso ocorresse fora desta jornada.

Há dois pontos bastante discutíveis nesta previsão normativa.

Um deles é o fato de se prever tal uso fora de uma jornada de trabalho que, a princípio, não seria objeto de controle, como se salientou acima, não podendo, portanto, formalmente servir de parâmetro para se fixar o momento em que tal uso estaria fora dela.

Outro atine à fragilidade de uma posição segundo a qual o teletrabalhador, aquele que, pela própria natureza da sua atividade - que depende do uso de tecnologias de informação e de comunicação, nos termos da respectiva regulamentação - artigo $4^{\circ}$,

Laborare. Ano IV, Número 6, Jan-Jun/2021, pp. 69-89. ISSN 2595-847X. https://revistalaborare.org/ DOl: https://doi.org/10.33637/2595-847x.2021-61 
$\S 1^{\circ}$ da MP n..$^{\circ}$ 927/20 e o artigo 75-B da CLT -, vale-se de tais equipamentos digitais diariamente, não ser remunerado pelo tempo em que utiliza estes equipamentos.

Impende destacar, ainda, que ambas as modificações da jornada do teletrabalhador ensejam questionamento quanto à sua constitucionalidade.

A modificação referente à inaplicabilidade da limitação da jornada de trabalho do teletrabalhador seja ela do regime de telemarketing, seja a geral de oito horas, provoca questionamento acerca da sua constitucionalidade, por permitir, ainda que indiretamente, uma jornada excessivamente elastecida e não integralmente remunerada.

Essas características representariam, para parcela considerável da doutrina, verdadeiro menoscabo de direitos fundamentais do teletrabalhador, a saber: ao respeito ao limite da jornada de trabalho e ao meio ambiente hígido do trabalho, nos termos do artigo $7^{\circ}$, XIII e XXII da $\mathrm{CF} / 88$.

No que tange ao uso de tecnologias digitais, as críticas são ainda mais severas: a essência da atividade do teletrabalhador passa pelo uso delas, não se justificando a distinção entre trabalho durante a jornada e fora dela, para efeito de remuneração, pois ambas as situações configuram típica prestação de serviços.

Nesse sentido, haveria, para número robusto de doutrinadores, violação por esta previsão normativa a preceitos constitucionais, em especial da remuneração pelo labor extraordinário (art. $7^{\circ}, \mathrm{XVI}$ da $\mathrm{CF} / 88$ ).

Vale ressaltar que a jornada de trabalho limitada, sem prorrogações indevidas ou não remuneradas, representa relevante instrumento de preservação da saúde do trabalhador, pois essencial para a prevenção da sua deterioração. Saúde esta que constitui direito dotado de proteção constitucional, como salientado anteriormente.

Raimundo Simão de Melo esclarece a relevância deste caráter preventivo, nos seguintes termos:

Nessa ótica insere-se um novo contexto em que se prioriza a prevenção em detrimento das reparações de caráter individual, que, por mais vantajosas que sejam, jamais ressarcirão os prejuízos decorrentes dos acidentes de trabalho que, inexoravelmente, atingem os trabalhadores nos aspectos humanos, sociais e econômicos; atingem as empresas financeiramente, e o

Laborare. Ano IV, Número 6, Jan-Jun/2021, pp. 69-89. ISSN 2595-847X. https://revistalaborare.org/ DOl: https://doi.org/10.33637/2595-847x.2021-61 
próprio Estado, que responde, finalmente, pelas mazelas sociais decorrentes. (MELO, 2008, p. 28)

Sublinhe-se, em tempo, que a existência de previsão legal isolada que permita o elastecimento da jornada, assim como o descumprimento de outras normas de saúde e segurança no trabalho, não autoriza o empregador a menoscabar por completo seu dever geral de manutenção do meio ambiente do trabalho hígido, dever decorrente de preceito constitucional expresso, supramencionado.

Nesse sentido, esclarecedores os ensinamentos de Guilherme Guimarães Feliciano e de Paulo Roberto Lemgruber Ebert, em artigo sobre o tema:

Voltamos, pois, às considerações que vínhamos de apresentar no tópico anterior, à luz da gestão jurídica dos riscos e das consequentes responsabilidades. Caso tais obrigações essenciais não sejam observadas pelos empresários, ter-se-á a instalação de risco proibido nos ambientes de trabalho por eles administrados, com degradação ambiental de base antrópica que permite considerá-los poluído inclusive para os efeitos da Lei n. 6.938/1981 -, comprometendo potencialmente a vida, a saúde, a integridade psicofísica e/ou o bem-estar não apenas dos trabalhadores (subordinados ou não), mas também de toda a comunidade de entorno, mormente no atual contexto de transmissão comunitária do novo coronavírus. Os estabelecimentos de empresa não podem se transformar em 'caixas de ressonância' infectológicas (v. nota n. 19, supra); ou tampouco em 'criadouros de vírus', na expressão mais comum dos sanitaristas. E a responsabilidade primeira por essa condição geral de assepsia, especialmente do ponto de vista jurídico, é precisamente do empresário (ou de quem a ele esteja equiparado: art. $2^{\circ}, \S 1^{\circ}$, da CLT). (FELICIANO e EBERT, 2020, p. 14-15)

Trata-se, em resumo, da necessidade do respeito ao que Ney Stany Morais Maranhão define como "ousado projeto neoconstitucionalista, plenamente adequado à realidade brasileira" (MARANHÃO, 2010).

Dito de outro modo: há fortes dúvidas quanto à constitucionalidade das normas "sub lúmen", permitindo o elastecimento excessivo e não remunerado da jornada do teletrabalhador, no período de pandemia de Covid-19. Dúvidas que somente serão amenizadas quando a jurisprudência, ainda incipiente, sedimentar-se sobre o tema.

\section{UMA DURA, MAS EVITÁVEL, REALIDADE NACIONAL}

A opção realizada pelo governo federal, de buscar soluções por meio de restrições a medidas de saúde e segurança do trabalho, além de altamente polêmica, não era a

Laborare. Ano IV, Número 6, Jan-Jun/2021, pp. 69-89. ISSN 2595-847X. https://revistalaborare.org/ DOl: https://doi.org/10.33637/2595-847x.2021-61 
única possível, pois medidas completamente distintas eram não só possíveis, como desejáveis.

Nesse sentido, a salvaguarda dos empregos e da saúde no local de trabalho, que deveria ser prioritária, poderia ser alcançada por decisões muito diferentes das tomadas no Brasil, como foi feito em outros países do mundo.

Convém desse modo, examinar os efeitos insatisfatórios das medidas brasileiras, assim como as alternativas que havia para o combate aos terríveis desafios impostos pela pandemia de Covid-19 no mercado de trabalho.

\subsection{IMPACTOS DAS MEDIDAS BRASILEIRAS}

A opção do governo federal brasileiro, de flexibilizar as medidas de saúde e segurança do trabalho, basearam-se no pretexto de que constituiria a única maneira de se preservar as empresas e os empregos, durante o desafiador momento da pandemia de Covid-19.

Tratava-se, por conseguinte, da reafirmação do dogma econômico neoliberal, altamente cristalizado na equipe econômica do atual governo federal: somente pela supressão de direitos trabalhistas seria possível se atingir crescimento econômico ou, em cenário de crise, ao menos mitigar os efeitos desta.

Urge salientar, todavia, que, uma vez mais, como em todas as demais tentativas históricas de se atingir crescimento econômico com base em dogmas neoliberais, este caminho se revelou completamente equivocado: nenhum emprego foi mantido, nenhum crescimento foi atingido, somente um meio ambiente do trabalho precarizado resultou dessas medidas restritivas.

Prova disso é que a taxa de desemprego no Brasil, em vez de se manter estável, sofreu fortíssima elevação: dos 11,6\% registrados em fevereiro de $2020^{6}$, um mês antes do início oficial do estado de pandemia, passou-se ao assustador percentual atual de 14,6\%, em novembro de 2020, com aumento de 1,3\% em relação aos três trimestres anteriores e de $2,8 \%$ em relação ao mesmo trimestre de $2019^{7}$.

6 Segundo dados oficiais do IBGE, disponiveis em: https://www.ibge.gov.br/estatisticas/sociais/trabalho/9171pesquisa-nacional-por-amostra-de-domicilios-continua-mensal.html?edicao=27233\&t=destaques. Acesso em 13 dez 2020.

Laborare. Ano IV, Número 6, Jan-Jun/2021, pp. 69-89. ISSN 2595-847X. https://revistalaborare.org/ DOI: https://doi.org/10.33637/2595-847x.2021-61 
Isso sem contar os desalentados, por volta de $5 \%$, e de subempregados, que superam os $30 \%$ da força de trabalho brasileira.

No tocante ao crescimento econômico, já fragilizado antes da pandemia, registrou decréscimo de $0,27 \%$ no primeiro trimestre de 2020 , do qual dois meses fora dela houve um recuo de assustadores $10,90 \%$ no segundo trimestre de 2020 , e novo recuo de $3,90 \%$ no terceiro trimestre de $2020^{8}$.

Partindo-se, portanto, de um quadro já fortemente desolador antes da pandemia, sem qualquer perspectiva real de crescimento econômico, passou-se a um cenário aterrador, de explosão de desemprego e fortíssima retração econômica.

Conclui-se, naturalmente, que as medidas restritivas e de flexibilização de medidas de saúde e segurança do trabalho, adotadas pelo governo federal, revelaram-se um completo fiasco, pois nenhum efeito positivo causaram, pelo contrário: aumentaram a precarização do já combalido mercado de trabalho nacional.

\subsection{MEDIDAS ALTERNATIVAS POSSÍVEIS}

Ainda que se deva admitir que a pandemia de Covid-19 causaria, necessariamente, efeitos econômicos negativos como ocorreram em todo o mundo, fato é que a opção realizada pelo governo federal brasileiro revelou-se complemente equivocada, pois não preservou empregos ou condições do local de trabalho.

Havia, contudo, alternativas distintas para se enfrentar os inéditos desafios impostos pela pandemia, como se verificou em diversos países do mundo.

Na França, as medidas adotadas pela Lei de Emergência Sanitária demonstram as diferenças com o caso brasileiro: colocar seus empregados em teletrabalho se tornou obrigação, não opção do empregador; quando o teletrabalho não fosse possível, o empregador deveria garantir a saúde e segurança do trabalho, assegurando distanciamento entre os empregados e a higiene do local de trabalho.

Ainda examinando o caso francês, deve ser salientado que, em caso de impossibilidade de prestação dos serviços presenciais, foi prevista a interrupção do

7 Conforme dados oficiais do IBGE, disponíveis em: https://www.ibge.gov.br/estatisticas/sociais/trabalho/9171pesquisa-nacional-por-amostra-de-domicilios-continua-mensal.html?edicao=29513\&t=destaques. Acesso em 13 dez 2020.

8 De acordo com dados oficiais do IPEA, disponíveis em: http:/www.ipeadata.gov.br/exibeserie.aspx? serid=38414. Acesso em 13 dez 2020.

Laborare. Ano IV, Número 6, Jan-Jun/2021, pp. 69-89. ISSN 2595-847X. https://revistalaborare.org/ DOI: https://doi.org/10.33637/2595-847x.2021-61 
trabalho, com pagamento de indenização pelo seguro saúde do governo, com duração de 21 dias, renováveis quantas vezes fosse necessário.

$\mathrm{Na}$ hipótese de fechamento da empresa, o empregador teve que manter $70 \%$ do salário do empregado, o restante sendo pago pelo governo, por meio de segurodesemprego parcial. Aliás, os desempregados fizeram jus à percepção do segurodesemprego durante todo o período de confinamento social, estendendo, portanto, o prazo máximo original.

Medidas similares foram adotadas em outros países: nos Estados Unidos, um auxílio de mil dólares foi pago pelo governo aos trabalhadores.

$\mathrm{Na}$ Inglaterra, foi estendido o pagamento da licença médica a trabalhadores que não estivessem doentes, mas tiveram que se isolar em quarentena; foi facilitado o acesso a benefícios sociais para pessoas de baixa renda ou trabalhadores autônomos; houve apoio econômico do governo às pequenas empresas que concederam licença aos trabalhadores, com custeio pelo governo do afastamento dos trabalhadores por até 14 dias.

$\mathrm{Na}$ Espanha, houve, igualmente, extensão da licença médica para trabalhadores não doentes, mas que estivessem em isolamento preventivo, por ordem de autoridades.

Em Portugal, por fim, os trabalhadores que precisassem ficar em casa para cuidar de filhos menores de 12 anos, tiveram garantidos dois terços do salário, sendo um terço pago pelo governo; trabalhadores autônomos receberam do governo um auxílio financeiro, de até seis meses.

Percebe-se, por conseguinte, que, diversamente do caso brasileiro, em que se optou pela precarização das condições de trabalho como via para supostamente salvaguardar empregos, em vários países do mundo se optou por caminho diverso, de garantia efetiva dos empregos, por meio de pagamento de auxílios para empregados que tiveram que permanecer em casa, sem trabalhar, por um período.

O resultado foi um impacto bem mais efetivo dessas medidas na realidade do mercado de trabalho desses países: os recuos econômicos generalizados, naturalmente decorrentes da pandemia, não foram suficientes para criar um cenário de caos vivenciado no Brasil, onde a opção do governo só agravou a crise, em vez de mitigá-la.

Laborare. Ano IV, Número 6, Jan-Jun/2021, pp. 69-89. ISSN 2595-847X. https://revistalaborare.org/ DOI: https://doi.org/10.33637/2595-847x.2021-61 


\section{CONSIDERAÇÕES FINAIS}

A maneira como o Poder Executivo federal brasileiro enfrentou os efeitos da pandemia de Covid-19, na seara laboral, ensejou acalorada polêmica, pois realizou clara opção por abordagem baseada na flexibilização de normas trabalhistas, em prol de pretensa manutenção dos empregos, que ao final não se verificou.

Isto ocorreu mesmo no que tange ao meio ambiente do trabalho, com relação ao qual se esperava que houvesse um incremento, não uma mitigação, das normas de proteção à saúde e segurança do trabalho.

Como examinado acima, esta mitigação se deu por diferentes medidas, todas sofrendo forte questionamento quanto à sua constitucionalidade, em razão dos riscos acrescidos de contaminação dos trabalhadores na nova realidade laboral, ameaçada por vírus altamente contagioso e demandando adaptação.

Pode-se concluir, por um lado, que estas medidas padecem de vícios inarredáveis de inconstitucionalidade, por serem inefavelmente incompatíveis com os preceitos constitucionais que regem o meio ambiente do trabalho no Brasil, especialmente o dever do empregador de zelar pela sua higidez, contido no artigo $7^{\circ}$, XXII da $\mathrm{CF} / 88$.

Por outro lado, essa via de precarização das condições de trabalho como pretenso caminho para preservação dos empregos se revelou totalmente inócua, pois houve uma explosão do desemprego no país, com fortíssima retração econômica, diversamente do que ocorreu em outros países do mundo, que optaram por via distinta, de salvaguarda da renda dos trabalhadores durante a pandemia de Covid-19, logrando atenuar os seus efeitos mais deletérios no mercado de trabalho.

\section{REFERÊNCIAS BIBLIOGRÁFICAS}

AMORIM JUNIOR, Cléber N. Segurança e saúde no trabalho: princípios norteadores. São Paulo: LTr, 2013.

BRANDÃO, Cláudio. Acidente do trabalho e responsabilidade civil do empregador. 3. Ed. São Paulo: LTr, 2009.

BRASIL. [Constituição (1988)]. Constituição da República Federativa do Brasil de 1988. Brasília, DF: Presidência da República, [2020]. Disponível em http://www.planalto.gov.br/ccivil_03/constituicao/constituicao.htm. Acesso em: 3 ago. 2020 .

Laborare. Ano IV, Número 6, Jan-Jun/2021, pp. 69-89. ISSN 2595-847X. https://revistalaborare.org/ DOI: https://doi.org/10.33637/2595-847x.2021-61 
. Decreto-Lei n. ${ }^{\circ}$ 5.452, de $1^{\circ}$ de maio de 1943. Aprova a Consolidação das Leis do Trabalho. Rio de Janeiro: Presidência da República [2020]. Disponível em http://www.planalto.gov.br/ccivil_03/decreto-lei/del5452.htm. Acesso em: 3 ago. 2020 .

- Medida Provisória n. ${ }^{\circ}$ 927, de 18 de março de 2020. Brasília, DF: Presidência da República, [2020]. Disponível em: http://www.planalto.gov.br/ccivil_03/_ato2019-2022/2020/Mpv/mpv927.htm. Acesso em: 3 ago. 2020.

CARDIM, Sérgio R. do N.; MARINO, Simone V. L. As medidas trabalhistas adotadas no Brasil e na França durante a pandemia de covid-19. Migalhas, 22 jun 2020. Disponível em https://migalhas.uol.com.br/depeso/329361/as-medidastrabalhistas-adotadas-no-brasil-e-na-franca-durante-a-pandemia-de-covid-19. Acesso em 13 dez 2020.

FELICIANO, Guilherme G.; EBERT, Paulo R. L. Coronavirus e meio ambiente de trabalho: De pandemias, pantomimas e panaceias. Remir Trabalho, 22.5.2020. Disponível em: http://www.eco.unicamp.br/remir/index.php/saude-e-seguranca-notrabalho/172-coronavirus-e-meio-ambiente-de-trabalho-de-pandemias-pantomimas-epanaceias. Acesso em: 9 ago. 2020.

FELICIANO, Guilherme G.; TRINDADE, Rodrigo. COVID-19 e direitos humanos: sob as luzes de Filadélfia. Migalhas, 10.5.2020. Disponível em: https://www.migalhas.com.br/depeso/326480/covid-19-e-direitos-humanos-sob-asluzes-de-filadelfia. Acesso em: 8 ago. 2020.

IBGE - INSTITUTO BRASILEIRO DE GEOGRAFIA E ESTATÍSTICA. Pesquisa Nacional por Amostra de Domicílios Contínua. Brasília, 2020.

IPEA - INSTITUTO DE PESQUISA ECONÔMICA APLICADA. Ipeadata. Brasília, 2020.

MARANHÃO, Ney S. M. Responsabilidade civil objetiva pelo risco da atividade: Uma perspectiva civil-constitucional. São Paulo: GEN/Método. 2010.

MARCHESAN, Ricardo. Coronavírus: EUA e países europeus vão bancar trabalhador que ficar em casa. UOL, 17 mar 2020. Disponível em https://economia.uol.com.br/noticias/redacao/2020/03/17/medidas-governocoronavirus-trabalho.htm . Acesso em $11 \mathrm{dez} 2020$.

MELO, Raimundo S. Adequação do meio ambiente do trabalho em tempos de Covid-19. Consultor Jurídico, 29.5.2020. Disponível em: 
https://www.conjur.com.br/2020-mai-29/reflexoes-trabalhistas-adequacao-meioambiente-trabalho-tempos-covid-19. Acesso em: 7 ago. 2020.

MELO, Raimundo S. Direito ambiental do trabalho e a saúde do trabalhador. 3 . ed. São Paulo: LTr, 2008.

OLIVEIRA, Sebastião G. de. Indenizações por acidente do trabalho ou doença ocupacional. São Paulo: LTr, 2005.

SILVA, José A. R. de O. A saúde do trabalhador como um direito humano. São Paulo: LTr, 2008.

Recebido: 04/09/2020

Revisado: 05/02/2021

Aprovado: 31/01/2021 